\title{
Metabolic engineering of Escherichia coli for de novo production of 3-phenylpropanol via retrobiosynthesis approach
}

\author{
Zhenning Liu' ${ }^{1}$ Xue Zhang ${ }^{1}$, Dengwei Lei ${ }^{1}$, Bin Qiao' ${ }^{1}$ and Guang-Rong Zhao ${ }^{1,2^{*}}$ (1)
}

\begin{abstract}
Background: 3-Phenylpropanol with a pleasant odor is widely used in foods, beverages and cosmetics as a fragrance ingredient. It also acts as the precursor and reactant in pharmaceutical and chemical industries. Currently, petroleumbased manufacturing processes of 3-phenypropanol is environmentally unfriendly and unsustainable. In this study, we aim to engineer Escherichia coli as microbial cell factory for de novo production of 3-phenypropanol via retrobiosynthesis approach.
\end{abstract}

Results: Aided by in silico retrobiosynthesis analysis, we designed a novel 3-phenylpropanol biosynthetic pathway extending from L-phenylalanine and comprising the phenylalanine ammonia lyase (PAL), enoate reductase (ER), aryl carboxylic acid reductase (CAR) and phosphopantetheinyl transferase (PPTase). We screened the enzymes from plants and microorganisms and reconstructed the artificial pathway for conversion of 3-phenylpropanol from L-phenylalanine. Then we conducted chromosome engineering to increase the supply of precursor L-phenylalanine and combined the upstream L-phenylalanine pathway and downstream 3-phenylpropanol pathway. Finally, we regulated the metabolic pathway strength and optimized fermentation conditions. As a consequence, metabolically engineered $E$. coli strain produced $847.97 \mathrm{mg} / \mathrm{L}$ of 3-phenypropanol at $24 \mathrm{~h}$ using glucose-glycerol mixture as co-carbon source.

Conclusions: We successfully developed an artificial 3-phenylpropanol pathway based on retrobiosynthesis approach, and highest titer of 3-phenylpropanol was achieved in E. coli via systems metabolic engineering strategies including enzyme sources variety, chromosome engineering, metabolic strength balancing and fermentation optimization. This work provides an engineered strain with industrial potential for production of 3-phenylpropanol, and the strategies applied here could be practical for bioengineers to design and reconstruct the microbial cell factory for high valuable chemicals.

Keywords: 3-Phenylpropanol, Synthetic biology, Retrobiosynthesis, Metabolic engineering, Escherichia coli

\section{Introduction}

3-Phenylpropanol, which gives a pleasant hyacinthmignonette odor and an apricot-like taste, has been extensively used in foods, beverages and cosmetics as a

\footnotetext{
*Correspondence: grzhao@tju.edu.cn

${ }^{1}$ Frontier Science Center for Synthetic Biology and Key Laboratory of Systems Bioengineering (Ministry of Education), School of Chemical Engineering and Technology, Tianjin University, Yaguan Road 135, Jinnan District, Tianjin 300350, China

Full list of author information is available at the end of the article
}

fragrance ingredient by approval of the United States Food and Drug Administration (21 CFR 172.515) [1]. 3-Phenylpropanol is also the substrate for the production of a fragrance ingredient 3-phenylpropyl acetate [2], and a pharmaceutical phenprobamate, which is a central skeletal muscle relaxant for treatment of muscle cramps and spasticity [3, 4]. Moreover, 3-phenylpropanol acts as the reactant for the synthesis of amines, ethers, and other chemicals with applications in coatings, resins and pharmaceutical building blocks $[5,6]$. Just for uses

(C) The Author(s) 2021. This article is licensed under a Creative Commons Attribution 4.0 International License, which permits use, sharing, adaptation, distribution and reproduction in any medium or format, as long as you give appropriate credit to the original author(s) and the source, provide a link to the Creative Commons licence, and indicate if changes were made. The images or other third party material in this article are included in the article's Creative Commons licence, unless indicated otherwise in a credit line to the material. If material is not included in the article's Creative Commons licence and your intended use is not permitted by statutory regulation or exceeds the permitted use, you will need to obtain permission directly from the copyright holder. To view a copy of this licence, visit http://creativeco mmons.org/licenses/by/4.0/. The Creative Commons Public Domain Dedication waiver (http://creativecommons.org/publicdomain/ zero/1.0/) applies to the data made available in this article, unless otherwise stated in a credit line to the data. 
in fragrance industry, the global consumption of 3-phenylpropanol was estimated to range between 100 and 1000 metric tons per annum [7]. Currently, the manufacturing process for the production of 3-phenylpropanol is petroleum-based, commonly relying on the hydrogenation of cinnamaldehyde in the presence of metal catalysts $[8,9]$.

As an eco-friendly and economic approach, engineering microorganisms has become an attractive alternative to efficiently produce high-value compounds, such as flavors, fragrances, cosmetics, pharmaceuticals, solvents, biofuels and other chemicals [10-22]. Bioproduction of 3-phenylpropanol has been reported in Saccharomyces cerevisiae [23]. By introducing phenylalanine ammonia lyase (PAL) gene from Photorhabdus luminescens, aryl carboxylic acid reductase (CAR) gene from Nocardia sp., and phosphopantetheinyl transferase (PPTase) gene from Escherichia coli, engineered Saccharomyces cerevisiae produced $212.9 \mathrm{mg} / \mathrm{L}$ of 3-phenylpropanol from glucose [23, 24] (Fig. 1A). However, using the whole lyophilised $E$. coli cell extract expressing these three heterologous enzymes, the in vitro enzymatic reaction with substrate L-phenylalanine revealed that the major product was cinnamyl alcohol and 3-phenylpropanol was the byproduct [25]. It was likely that the enzymatic properties of the unknown endogenous enzymes involved in the 3-phenylpropanol biosynthetic pathway between $S$. cerevisiae and E. coli were seriously different, which hindered further improvement of 3-phenylpropanol production in microorganisms. Retrobiosynthesis is an approach for biosynthetic pathway design from target molecules to cellular metabolites, using the biotransformation rules that present the rearrangement of atoms and bonds in enzymatic reactions [26, 27]. With great potential in synthetic biology and metabolic engineering, retrobiosynthesis has been applied in the production of didanosine [28], 5-aminolevulinic acid [29], and short-chain primary amines [30]. Furthermore, the current development of retrobiosynthesis tools for biosynthesis of valuable chemicals $[27,31,32]$ provides a more feasible approach to rationally design a novel artificial pathway according to the available enzymatic reactions from databases, and then implement systems metabolic engineering strategies for efficient production of 3-phenylpropanol in microbes.

In this study, using the retrobiosynthesis analysis strategy, we designed a novel biosynthetic pathway and engineered an recombinant $E$. coli strain capable of de novo production of 3-phenylpropanol from glucose (Fig. 1B). First, we conducted in silico retrobiosynthesis of 3-phenylpropanol aided by RetroPath 2.0 software, and identified a candidate pathway from enumerated pathways. This pathway extended from L-phenylalanine and consisted of PAL, enoate reductase (ER), CAR and PPTase, which was different from previous reported pathway in yeast. Next, we refactored the designed pathway in E. coli by expressing the heterologous genes from different species. We constructed the de novo producing strain by chromosome engineering and tuned the expression pattern of the pathway genes. After the optimization of culture conditions, the engineered E. coli produced $847.97 \mathrm{mg} / \mathrm{L}$ of 3-phenylpropanol from glucose in $24 \mathrm{~h}$ of flask-shake fermentation, which is the highest titer achieved in microbial production of 3-phenylpropanol up to date.

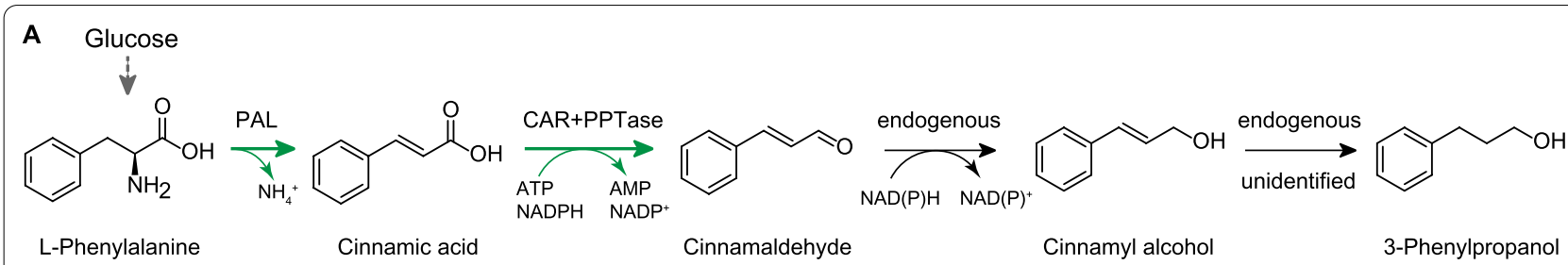

B Glucose

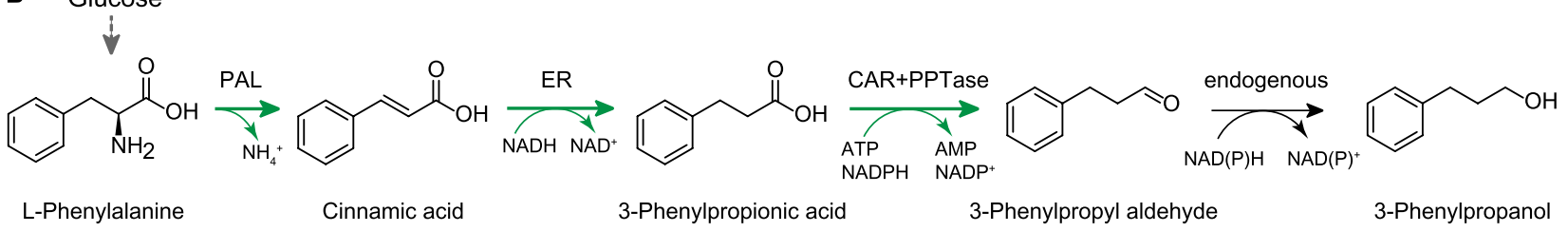

Fig. 1 The 3-phenylpropanol biosynthetic pathways. A The proposed pathway in S. cerevisiae [23, 24]. B The retrosynthetically designed artificial pathway in E. coli in this study. Green arrow indicated the heterologous enzymes: PAL L-phenylalanine ammonia lyase, CAR carboxylic acid reductase, PPTase phosphophantethinyl transferase, ER enoate reductase 


\section{Results and discussion}

\section{Retrobiosynthetic design of 3-phenylpropanol biosynthetic pathway}

Due to the lack of characterization for the natural pathway in plants and limited knowledge on established pathway for 3-phenylpropanol biosynthesis, we aimed to enumerate possible 3-phenylpropanol pathways from a retrobiosynthesis viewpoint. Using RetroPath 2.0 [33], an automated retrosynthesis workflow, we predicted potential pathways based on enormous amount of generative reactions in public databases [34], and two potential pathways were generated extending from the native L-phenylalanine metabolism in E. coli (Fig. 2, pathways I and II). We manually added two functional pathways (pathway III and IV) which were proposed previously in $E$. coli $[25]$ and yeast [23, 24], respectively, and four pathways were totally depicted.

As shown in Fig. 2, except for longer pathway II which underwent five steps, the other three pathways had the same length with similar reaction types. The $\alpha$-hydroxyl functionality can be obtained from an $\alpha$-aldehyde group catalyzed by $E$. coli endogenous aldo-keto reductases (AKRs, EC 1.1.1.346) or alcohol dehydrogenases (ADHs, EC 1.1.1.2) [35]. The difference among pathways I, III and IV was the order of the $\mathrm{C}=\mathrm{C}$ double bond hydrogenation and the carboxyl group reduction of cinnamic acid. Most of ERs work well at anaerobic environment and are not suitable for aerobic fermentation [36]. Recently, the CaER from Clostridium acetobutylicum showed the oxygen tolerance in conversion of cinnamic acid to 3-phenylpropionic acid in $E$. coli [37]. The substrates of CAR enzymes include both saturated or unsaturated acids, ensuring the selective reduction of carboxyl group [38]. Thus, pathway I was selected as the candidate one among four proposed pathways with confirmed enzymes for each step.

To validate the feasibility of the retrobiosynthetically designed pathway extending $E$. coli native L-phenylalanine metabolism for de novo production of 3-phenylpropanol, we divided the full pathway into the upstream pathway for L-phenylalanine biosynthesis from glucose and the downstream pathway for the 3-phenylpropanol biosynthesis from L-phenylalanine. These two pathways were retro-synthetically reconstructed and optimized for de novo production of 3-phenylpropanol in the following experiments.

\section{Reconstructing the downstream pathway} for 3-phenylpropanol biosynthesis from L-phenylalanine In our designed downstream pathway which comprised PAL, ER, CAR/PPTase, and endogenous alcohol dehydrogenases (ADHs) or aldo-keto reductases (AKRs), except for the previously reported CaER from Clostridium acetobutylicum which was suitable for the conversion of 3-phenylpropionic acid from cinnamic acid under aerobic conditions [37], the other suitable enzymes remain to be evaluated. The reductive reaction of carboxylic acid moiety of 3-phenylpropionic acid catalyzed by post-translationally PPTase-activated CAR is crucial for 3-phenylpropanol biosynthesis and five CARs from different species were chosen as candidates: SruCAR from Segniliparus rugosus [25], MsCAR from Mycobacterium smegmatis [39], SroCAR from Segniliparus rotundus [40], TtCAR from Thermothelomyces thermophila [41], and NcCAR from Neurospora crassa [42]. We predicted that the unknown endogenous ADHs or AKRs could catalyze the conversion of 3-phenylpropanol from 3-phenylpropyl aldehyde. Thus, we screened the CAR and PPTase sequentially. Firstly, we cloned five candidate $C A R$ genes into pETDuet-1, respectively, and transformed them together with the plasmid expressing the CaER gene and the EcPPTase gene of E. coli [41] in pCDFDuet-1, into E. coli BL21(DE3) to construct strains BTR01, BTR02, BTR03, BTR04 and BTR05. The fermentation was performed with supplementation of cinnamic acid, and the production of 3-phenylpropanol was analyzed by HPLC. Expectedly, as shown in Fig. 3A, five strains produced 3-phenylpropanol which has the same retention time as 3-phenylpropanol standard. The identity of 3-phenylpropanol was further confirmed by gas chromatography-mass spectrometry analysis (Additional file 1: Figure $\mathrm{S} 1$ ). The results indicated that the endogenous ADHs or AKRs actively worked as previous reports [13, 43] and that the ER, CAR and PPTase were essential for biosynthesis of 3-phenylpropanol when they were expressed in E. coli. As shown in Fig. 3B, compared to strain BTR01 which produced $148.34 \mathrm{mg} / \mathrm{L}$ of 3-phenylpropanol, strains BTR02, BTR03, BTR04 and BTR05 expressing different CARs genes produced less amounts of 3-phenylpropanol, ranging from 115.92 to $131.23 \mathrm{mg} / \mathrm{L}$, indicating SruCAR was superior to the others in the biosynthetic pathway of 3-phenylpropanol from cinnamic acid. The minor amount accumulation of byproduct cinnamyl

\footnotetext{
(See figure on next page.)

Fig. 2 Enumeration of 3-phenylpropanol biosynthetic pathways. All of the four pathways were extending from L-phenylalanine and phenylpyruvate in E. coli native L-phenylalanine metabolism and depicted by RetroPath 2.0 [33]. Pathway I and II was automatically generated by retrosynthesis workflow of RetroPath 2.0 based on reactions from databases. Pathway III and IV were functional pathways in previous reports [23-25]. The reactions in pathways were represented by EC numbers. The compound names are as follows: 3-phenylpropanol (A), 3-phenylpropyl aldehyde (B), cinnamyl alcohol (C), 3-phenylpropionic acid (D), cinnamaldehyde (E), cinnamic acid (F), L-phenylalanine (G), 3-phenyllactic acid (H), phenylpyruvate (I)
} 


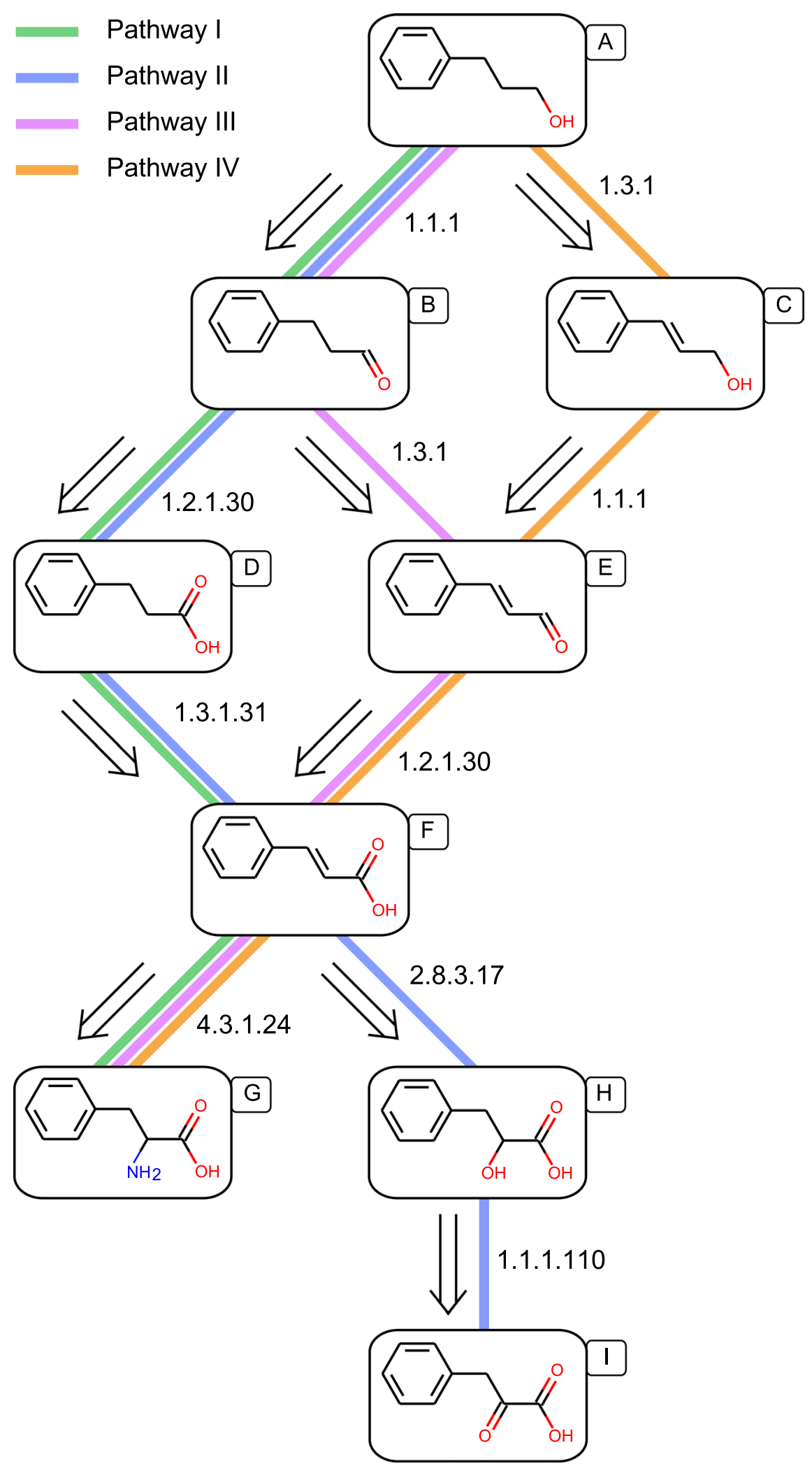

Fig. 2 (See legend on previous page.) 

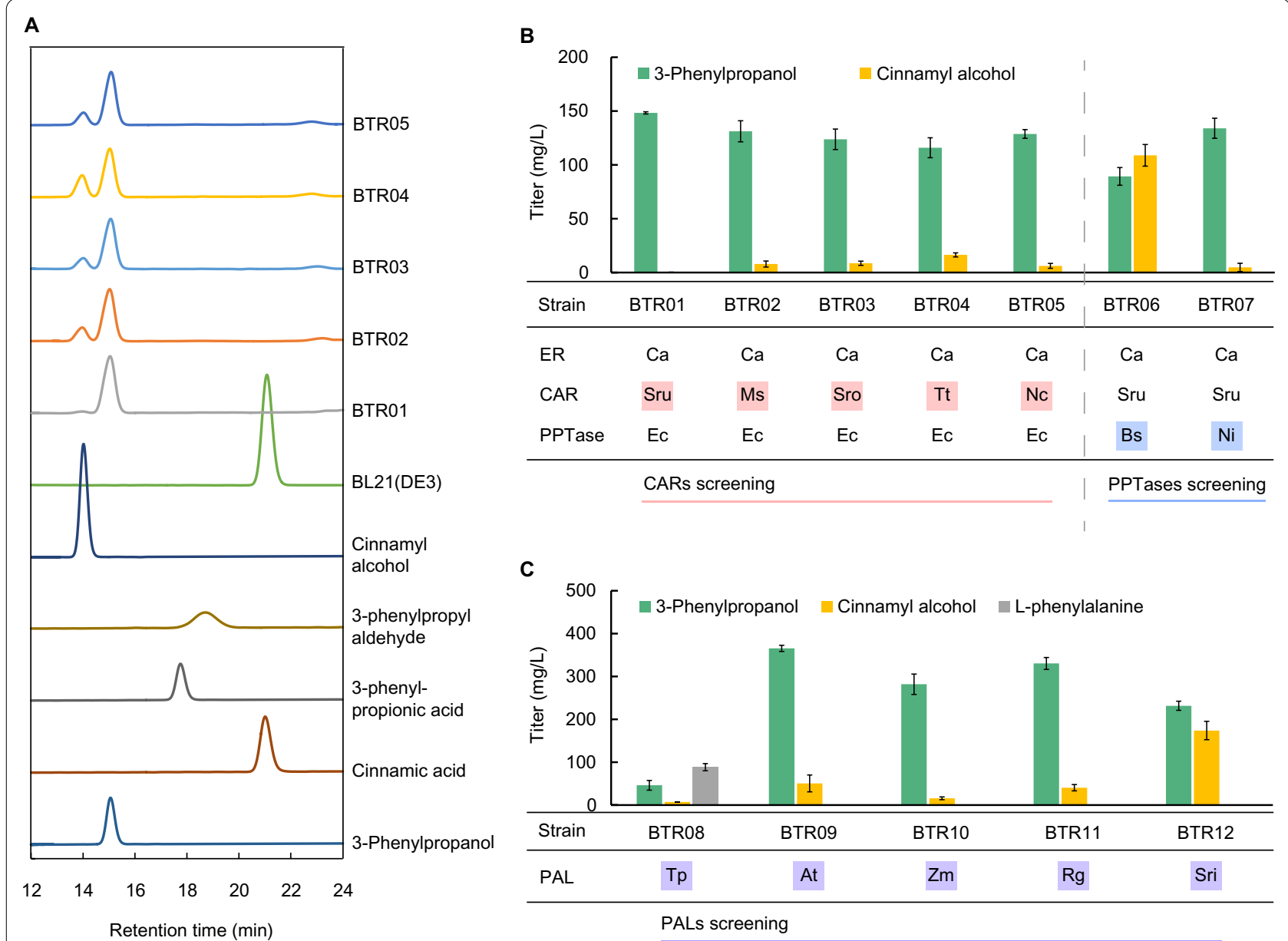

Fig. 3 Reconstruction of the downstream pathway of 3-phenylpropanol biosynthesis from L-phenylalanine. A HPLC spectra of the culture supernatants of strains BTR01, BTR02, BTR03, BTR04 and BTR05, which harbored CaER, EcPPTase and various CARs. B Performance of strains harboring various CARs and PPTases. $200 \mathrm{mg} / \mathrm{L}$ of cinnamic acid was supplemented in the medium. C Performance of strains with various PALs. $500 \mathrm{mg} / \mathrm{L}$ of L-phenylalanine and $0.1 \mathrm{mM} \mathrm{IPTG}$ were supplemented in the medium. All samples were collected and analyzed at $48 \mathrm{~h}$. Source organisms of pathway enzymes are abbreviated: Ca, Clostridium acetobutylicum; Ec, Escherichia coli; Sru, Segniliparus rugosus; Ms, Mycobacterium smegmatis; Sro, Segniliparus rotundus; Tt, Thermothelomyces thermophile; Nc, Neurospora crassa; Bs, Bacillus subtilis; Ni, Nocardia iowensis; Tp, Trifolium pratense; At, Arabidopsis thaliana; Zm, Zea mays; Rg, Rhodotorula glutinis; Sri, Streptomyces rimosus

alcohol was probably caused by the promiscuity of CAR which catalyzed the reduction of carboxylic acid moiety of cinnamic acid into the formation of cinnamyl aldehyde followed by the endogenous reduction or dehydrogenation as previous report [25].

Considering the multiple functionality of PPTases involved in modification and regulation on activities and regeneration of polyketide synthases [44], we next investigated BsPPTase from Bacillus subtilis [45] which was commonly employed in the heterologous production of polyketides in E. coli and yeast [46], and NiPPTase from Nocardia iowensis [40] which was frequently used for activation of heterologous CARs [38]. As shown in Fig. 3B, BTR06 expressing BsPPTase and
BTR07 expressing NiPPTase produced $89.30 \mathrm{mg} / \mathrm{L}$ and $133.99 \mathrm{mg} / \mathrm{L}$ of 3-phenylpropanol, respectively. NiPPase seemed nearly comparable to EcPPTase for production of 3-phenylpropanol, while BsPPTase was quite incompetent to do the work as large amount of cinnamyl alcohol was accumulated, indicating the incompatibility between BsPPTase and SruCAR, or the unknown effects of BsPPTase on the metabolic pathway. Taken together, we confirmed the novel biosynthetic pathway of 3-phenylpropanol composed of CaER, SruCAR and EcPPTase, which can efficiently catalyze the formation of 3-phenylpropanol from cinnamic acid in E. coli, with no accumulation of the precursor cinnamic acid and byproduct cinnamyl alcohol in strain BTR01. 
PAL enzyme links 3-phenylpropanol biosynthetic pathway to $E$. coli endogenous metabolite L-phenylalanine by converting L-phenylalanine to cinnamic acid (Fig. 1B). In order to eliminate the bottleneck at this metabolic node, we introduced different PALs into the designed pathway and investigated their effects on 3-phenylpropanol production. Three identified plant PALs (TpPAL1 [47], AtPAL2 [48], ZmPAL2 [49]) and one characterized Rhodotorula TAL (RgTAL[37]), together with one putative PAL from Streptomyces rimosus [50] were investigated. We cloned candidate PALs genes or TAL gene into pRSFDuet-1 and transformed them into strain BTR01 to obtain strains BTR08, BTR09, BTR10, BTR11 and BTR12 (Fig. $3 C$ ), respectively. We added L-phenylalanine in the cultivation medium, and measured the metabolites after fermentation. As shown in Fig. 3C, all resulting strains harboring tested PALs or TAL produced 3-phenylpropanol from precursor L-phenylalanine. However, the contribution of different PALs to the formation of 3-phenylpropanol remarkably varied. Strain BTR08 showed the lowest titer of 3-phenylpropanol $(46.20 \mathrm{mg} / \mathrm{L})$, while strains BTR10, BTR11 and BTR12 produced large amounts of 3-phenylpropanol, $281.90 \mathrm{mg} / \mathrm{L}, 330.36 \mathrm{mg} / \mathrm{L}$ and $231.66 \mathrm{mg} / \mathrm{L}$, respectively. Strain BTR09 produced highest 3-phenylpropanol at the titer of $365.59 \mathrm{mg} / \mathrm{L}, 6.9$ fold higher than that by strain BTR08, without the accumulation of cinnamic acid, indicating that AtPAL2 from A. thaliana was the most efficient and suitable in the designed biosynthetic pathway.

By experimental production of 3-phenylpropanol from L-phenylalanine in E. coli, we demonstrated the feasibility and high performance of designed pathway I. For pathway III in previous study [25], the low activities of $E$. coli endogenous $\mathrm{C}=\mathrm{C}$ double-bond reductases might lead to the formation of cinnamyl alcohol instead of 3-phenylpropanol as the major product. As for pathway IV in yeast, the endogenous reductases might be more active than those in E. coli, and more 3-phenylpropanol was produced $[23,24]$. Unidentified endogenous $C=C$ double-bond reductases and the redox status might differ between $E$. coli cells and yeast cells, which resulted in different final products. CaER is an excellent reductase and could efficiently convert cinnamic acid to 3-phenylpropionic acid under aerobic conditions [37]. When the CaER was introduced to construct pathway I, the metabolic limitation at the $\mathrm{C}=\mathrm{C}$ double-bond reduction node in 3-phenylpropanol biosynthetic pathway was removed, and 3-phenylpropanol was achieved as the major product in E. coli (Fig. 3C). Thus, we refactored the downstream pathway for 3-phenylpropanol biosynthesis which comprised AtPAL2, CaER, SruCAR, and EcPPTase, and attempted to optimize the upstream pathway in $E$. coli in following study.

\section{Chromosome engineering of upstream pathway for the de novo biosynthesis of 3-phenylpropanol}

In order to achieve the de novo biosynthesis of 3-phenylpropanol, we used L-phenylalanine overproducing chassis BWH18 from our previous work [51] to enlarge the metabolic flux to upstream L-phenylalanine pathway from glucose by chromosome engineering. Since strain BWH18 was derived from $E$. coli BW25113 by integrating the $\operatorname{aro} G^{\mathrm{fbr}}-p h e A^{\mathrm{fbr}}$ genes and deleting the $t y r A$ gene to relieve the feedback and competitive inhibitions, we integrated T7 RNA polymerase gene in BWH18 chromosome to confer 3-phenylpropanol biosynthetic genes of the downstream pathway to be controlled under T7 promoter, generating strain BTR13. Four potential targets can be disrupted to enhance the metabolic flux to L-phenylalanine from glucose in E. coli (Fig. 4A). Phosphoenolpyruvate (PEP) is one precursor for L-phenylalanine biosynthesis, and the PEP-dependent phosphotransferase system (PTS) is a major system for glucose transport, in which nearly $50 \%$ of PEP was consumed as the phosphate donor [52]. Thus we deleted the $p t s G$ gene of strain BTR13 to construct strain BTR14, and the titer of L-phenylalanine was not obviously changed (Fig. 4B). PEP is also consumed and converted to pyruvate in glycolysis [53]. In order to conserve PEP, we deleted the $p y k A$ and $p y k F$ genes encoding pyruvate kinases, and the triple deletion strain BTR16 produced $535.87 \mathrm{mg} / \mathrm{L}$ of L-phenylalanine, a $36.90 \%$ increase than strain BTR13, in consistent with previous reports $[54,55]$. L-Phenylalanine biosynthesis is negatively regulated by the repressor TyrR targeting the transcriptional expression of the aroG and aroF genes encoding 3-deoxy-arabino-heptulonate 7-phosphate (DAHP) synthase isoenzymes and the aroL gene encoding shikimate kinase [56]. We deleted the tyrR gene in combination with disruption of the $p t s G$ and/or pyk genes to construct strains BTR17, BTR18 and BTR19. Compared to strain BTR13, the combinatorial effects of gene disruption enabled $47.00 \%, 69.68 \%$ and $94.73 \%$ improvement of L-phenylalanine production in strains BTR17, BTR18 and BTR19, respectively. The quadruple deletion strain BTR19 exhibited the highest production of L-phenylalanine with a titer of $762.25 \mathrm{mg} / \mathrm{L}$.

We then introduced the downstream 3-phenylpropanol pathway to each of aforementioned L-phenylalanine overproducing strains, and examined the compatibility of the downstream pathway with various upstream pathways by comparing the productive performance of engineered strains. As shown in Fig. 4C, strain BTR20 produced $160.05 \mathrm{mg} / \mathrm{L}$ of 3-phenylpropanol, and a large amount of byproduct cinnamyl alcohol $(224.03 \mathrm{mg} / \mathrm{L})$ was accumulated, indicating that the chassis strain BTR13 was not fit for producing 3-phenylpropanol. When the $p t s G$ and/or pyk genes were deleted, the byproduct faded significantly, 


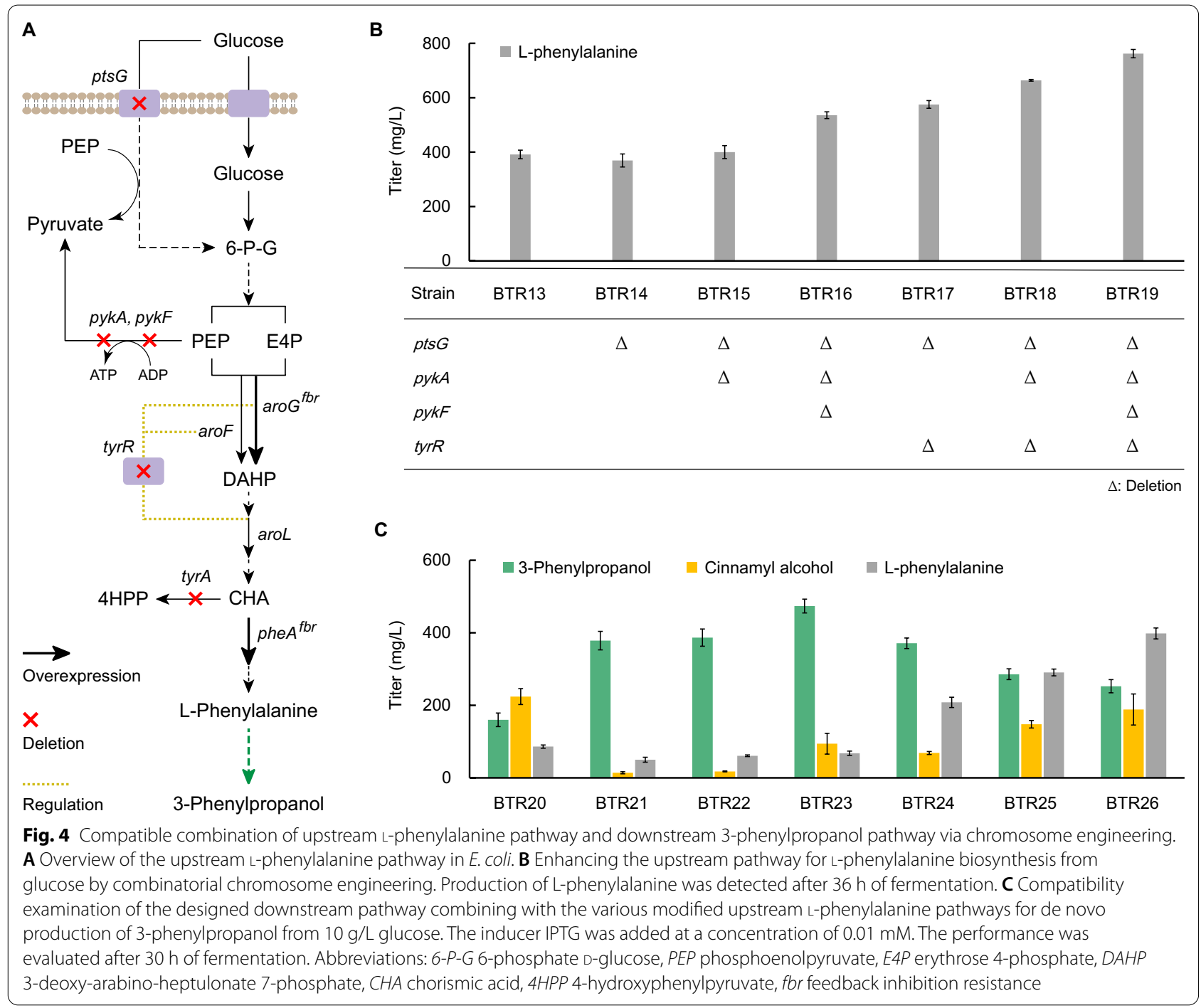

and the production of 3-phenylpropanol was greatly increased in strains BTR21-BTR23, of which, strain BTR23 with the triple deletion of the $p t s G, p y k F$ and $p y k A$ genes gave the highest production of 3-phenylpropanol with the titer of $473.75 \mathrm{mg} / \mathrm{L}, 2.0$-fold higher than BTR20.

Although deleting the tyrR gene benefited the biosynthesis of L-phenylalanine in strains BTR17, BTR18, and BTR19, both the precursor L-phenylalanine and byproduct cinnamyl alcohol were seriously accumulated in strains BTR24, BTR25, and BTR26, and the production of 3-phenylpropanol was not improved as the same as that of L-phenylalanine in the chassis strains, revealing the incompatibility between the artificial biosynthetic pathway of 3-phenylpropanol and the physiological status of chassis strains of BTR24, BTR25, and BTR26. It was speculated that the metabolic flux to the upstream pathway for L-phenylalanine biosynthesis exceeded that to the downstream pathway for 3-phenylpropanol biosynthesis. In addition to genes involved in L-phenylalanine metabolism, the TyrR regulon consists of a diverse range of members awaiting to be identified $[57,58]$, which might indirectly influence 3-phenylpropanol biosynthesis.

\section{Balancing the metabolic strength of the downstream 3-phenylpropanol pathway}

Based on the auxiliary function of EcPPTase for activation of SruCAR, we proposed that high overexpression of EcPPTase would be unnecessary. The gene encoding EcPPTase was removed from the expression plasmid and integrated in the chromosome of engineered E. coli strain. As expectedly, the resulting strain BEL09 produced similar amount of 3-phenylpropanol ( $461.25 \mathrm{mg} / \mathrm{L})$ to strain BTR23 (473.75 mg/L). To alleviate the metabolic burden caused by three expression plasmids, we regulated the metabolic strength of the AtPAL2, CaER and 


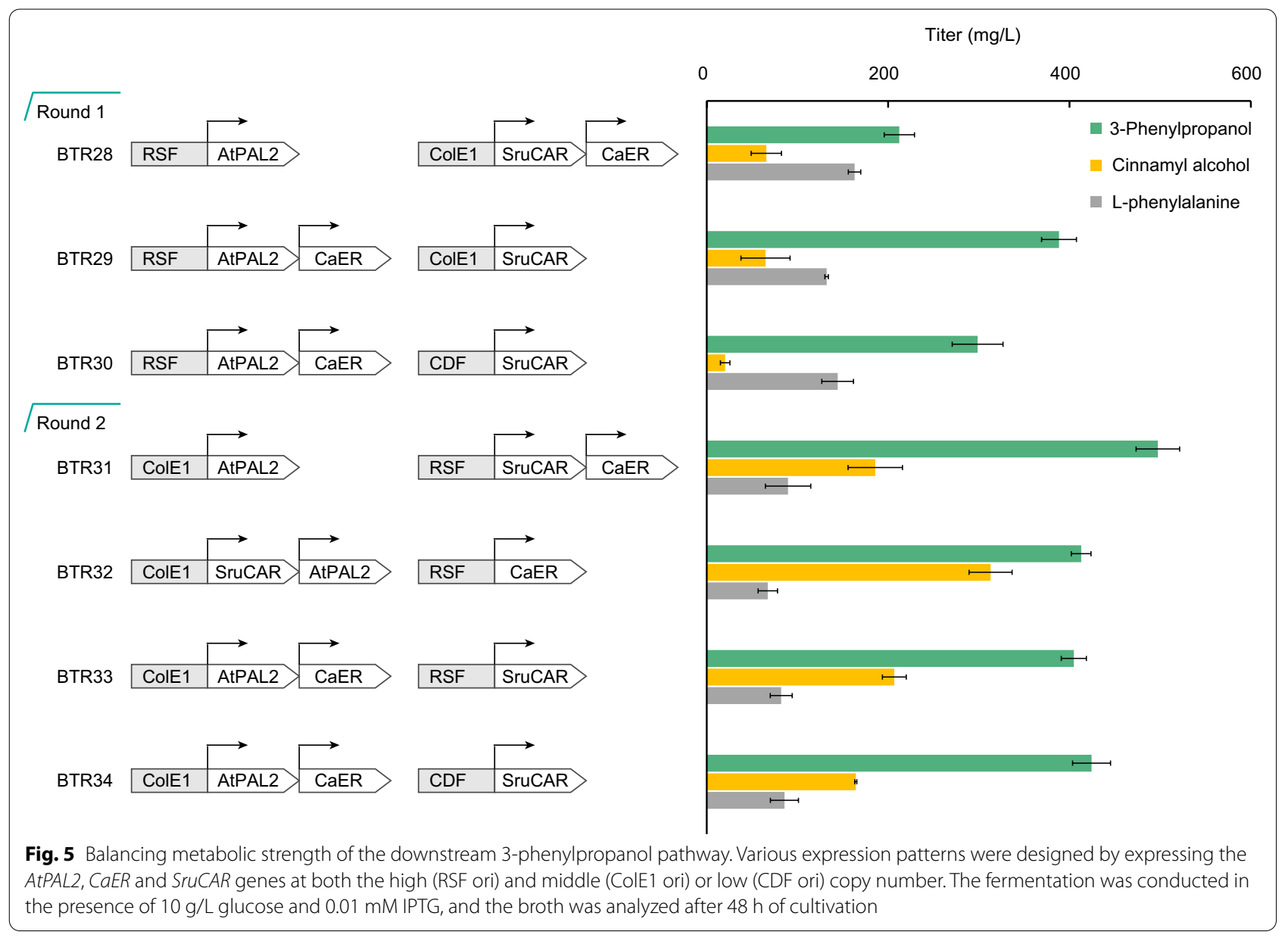

SruCAR genes using two compatible plasmids derived from pRSFDuet-1 (high copy number, RSF ori), pETDuet-1 (middle copy number, ColE1 ori) or pCDFDuet-1 (low copy number, CDF ori) (Fig. 5). We did two rounds of regulation tests. In the first round of test, compared to strain BTR28, coexpressing the AtPAL2 and CaER genes in pRSFDuet-1 increased the production of 3-phenylpropanol, whenever the SruCAR gene was expressed in pETDuet-1 or pCDFDuet-1. Since L-phenylalanine precursor was accumulated in tested strains of the first round, the second round of test was carried out by down-regulating expression of the AtPAL2 gene with or without the CaER or SruCAR genes in ColE1-originated middle copy number plasmid pETDuet-1. Compared to the strains tested in the first round, accumulation of L-phenylalanine was decreased, while concentration of cinnamyl alcohol was increased in strains BTR31-BTR34. Among them, strain BTR31 showed the best performance on fermentation, and produced $497.49 \mathrm{mg} / \mathrm{L}$ of 3-phenylpropanol, 1.3-fold higher amount than that of strain BTR28. The results indicated the expression of both $C a E R$ and SruCAR genes in pRSFDuet-1 was beneficial for higher production of 3-phenylpropanol. We tried to improve the production titer and reduce the accumulation of byproduct by optimizing fermentation conditions in next section.

\section{Optimizing fermentation conditions for further improvement of 3-phenylpropanol production}

Temperature is a critical parameter for cell growth and end product biosynthesis in fermentation process, and we firstly tested its effect on production of 3-phenylpropanol. We carried the fermentation at the temperature of $22{ }^{\circ} \mathrm{C}, 30{ }^{\circ} \mathrm{C}$ and $37{ }^{\circ} \mathrm{C}$, respectively. Compared to fermentation at $30{ }^{\circ} \mathrm{C}$, glucose was not exhausted and the titer of 3-phenylpropanol was dramatically decreased, while cinnamyl alcohol was greatly accumulated, indicating that lower the fermentation temperature to $22{ }^{\circ} \mathrm{C}$ resulted in a poor performance of E. coli strains and hampered 3-phenylpropanol biosynthesis. Contrarily, the fermentation at $37^{\circ} \mathrm{C}$ which is physiological temperature of $E$. coli improved 3-phenylpropanol production with a titer of $674.76 \mathrm{mg} / \mathrm{L}$ (Fig. 6), 31.77\% increase compared to that at $30{ }^{\circ} \mathrm{C}$, although along with the increase of cinnamyl alcohol 


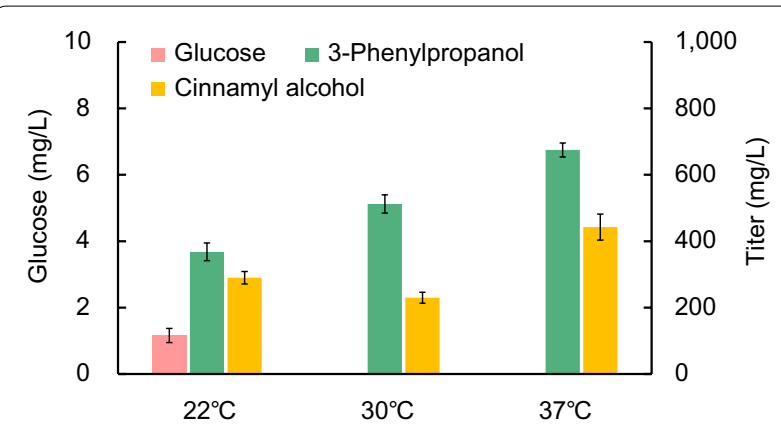

Fig. 6 Improvement of 3-phenylpropanol production by optimizing fermentation temperature. Strain BTR31 was cultivated at $22^{\circ} \mathrm{C}, 30^{\circ} \mathrm{C}$ and $37^{\circ} \mathrm{C}$, respectively, with supplementation of $10 \mathrm{~g} / \mathrm{L}$ glucose and $0.01 \mathrm{mM}$ IPTG. The fermentation broth were analyzed at $48 \mathrm{~h}$

accumulation. The results indicated that 3-phenylpropanol fermentation was more suitable to be conducted under the physiological temperature condition.
Glycerol is a byproduct of biodiesel production and should therefore be a potential attractive carbon source for the production of valuable chemicals [59]. Then, we tested the effects of taking glycerol with glucose as mixture carbon source on the fermentation of 3-phenylpropanol. As shown in Fig. 7, adding glycerol in mixed medium greatly reduced the accumulation of cinnamyl alcohol, compared to using glucose as the sole carbon source. However, higher ratios of glycerol/glucose (over at $1: 1, \mathrm{w} / \mathrm{w})$ had the tendency to reduce the production of 3-phenylpropanol and the utilization of glycerol. When the ratio of glycerol/glucose was at 3:1, 3-phenylpropanol was $549.75 \mathrm{mg} / \mathrm{L}, 35.17 \%$ decrease than that at $1: 1$. It indicated that glycerol was not directly suitable as a major carbon source because of the inherent carbon mechanism in E. coli [60]. Consequently, the combinatorial profit of using glycerol and glucose mixture as co-substrate was achieved with the ratio of 1:3 and the highest amount of 3-phenylpropanol was achieved at a level of $847.79 \mathrm{mg} / \mathrm{L}$, which was $21.82 \%$ higher than when glucose was used as the sole carbon source, meanwhile

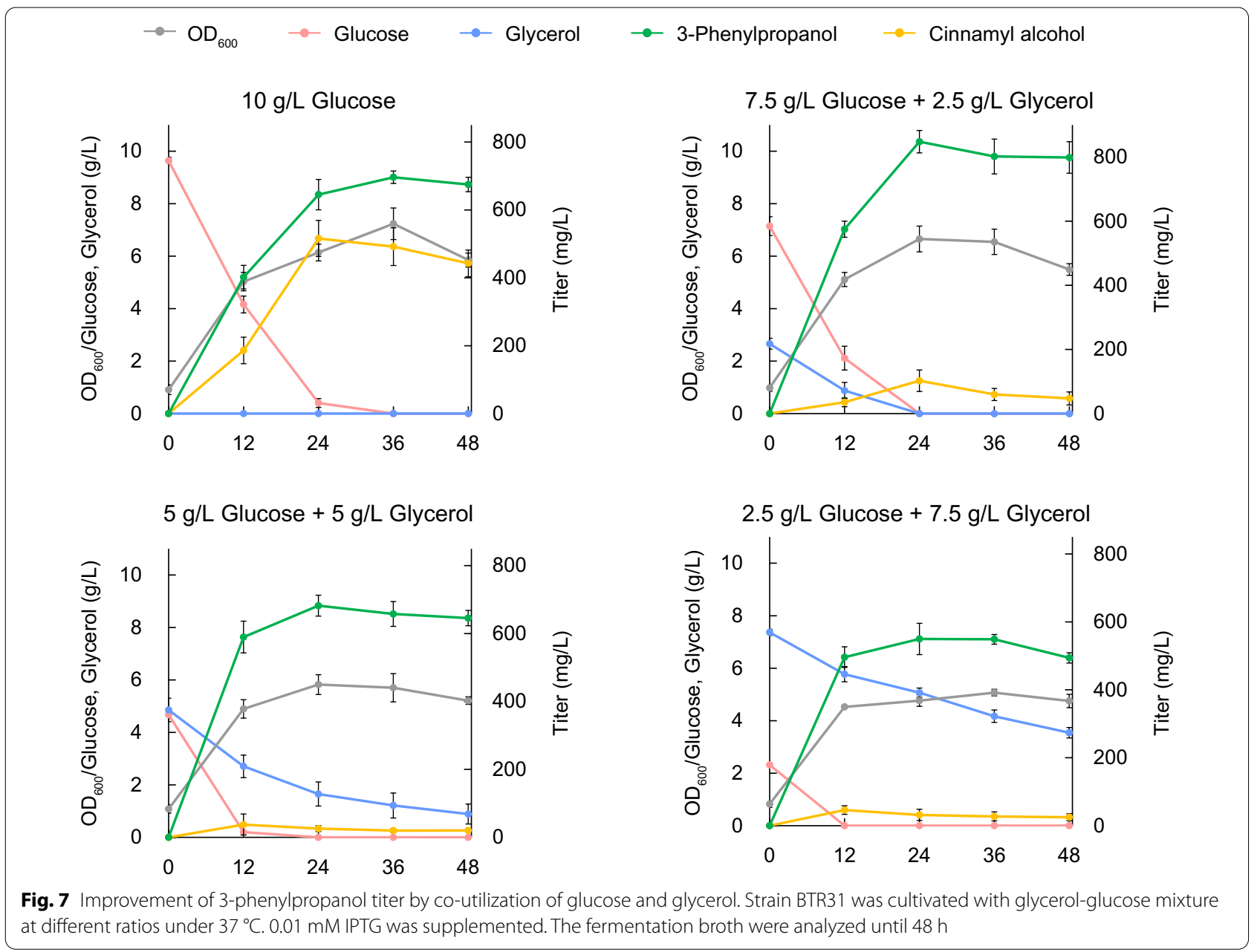


glycerol was completely consumed and the accumulation of unwanted byproduct cinnamyl alcohol was fairly low, representing a high efficiency of fermentation process.

\section{Conclusions}

In present study, a novel 3-phenypropanol biosynthetic pathway was designed by computer-aided retrobiosynthesis analysis, the highest titer for microbial production of 3-phenylpropanol was reported. By dividing the full de novo pathway at L-phenylalanine node, we employed systems metabolic engineering strategies to reconstruct microbial cell factory. We refactored the heterologous downstream pathway comprising AtPAL2, CaER, SruCAR and EcPPTase by changing the different enzymes from microbes and plants, and enhanced the upstream L-phenylalanine pathway by combinatorial chromosome engineering with multi-gene disruption. Tuning the compatibility between chassis strains and the designed downstream pathway, and balancing the expression pattern of pathway genes, resulted in an engineered E. coli strain, which produced $847.97 \mathrm{mg} / \mathrm{L}$ of 3-phenylpropanol under optimal fermentation conditions. Compared to previous report in which 3-phenypropanol was produced by S. cerevisiae [24], a three-fold increase of titer was achieved in our study. This work show the potential for novel metabolic pathway design of bio-based products via retrobiosynthesis approach, which could eliminate the gaps in pathway engineering caused by unidentified enzymes.

\section{Materials and methods}

In silico biodesign of artificial 3-phenylpropanol pathway

We depicted four 3-phenylpropanol biosynthetic pathways by RetroPath 2.0 [33]. Three input files, Source, Sink and Rules, were required for computation and output of pathways. The Source described the target compound 3-phenylpropanol. The Sink we used was derived from a Sink file that contains compounds from $E$. coli core metabolism ([61], https://github.com/brsynth/Retro PathRL). We added two compounds, phenylpyruvate and L-phenylalanine, to depict putative pathways extending from $E$. coli native L-phenylalanine metabolism. For generation of pathway I and II, we applied the Rules available at https://retrorules.org/dl, release rr02 [34], which contained a complete set of reactions extracted from public databases. For previously reported pathway III and IV, the Rules was encoded based on the involved reactions and generated by RetroRules online rule builder ([34], https://retrorules.org/diy). The parameters were predefined as follows for highly specific predictions: minimum rule diameter was ten, maximum pathway length was six, and number of structures to keep for next iteration was 20.

\section{Chemicals and reagents}

3-Phenylpropanol (99\% purity) was purchased from Heowns (China), cinnamic acid (99.5\% purity) was purchased from Haoshengjie Biotech (China), 3-phenylpropionic acid (99.88\% purity) and 3-phenylpropyl aldehyde (97\% purity) were purchased from Bidepharm (China), and cinnamyl alcohol (98\% purity) and L-phenylalanine (98\% purity) were purchased from Dingguo Changsheng Biotech (China). Acetonitrile, trifluoroacetic acid and ethyl acetate (HPLC grade) were purchased from Tianjin Jiangtian Chemical Technology (China). Phanta Max Super-Fidelity DNA Polymerase and Taq Polymerase using in polymerase chain reaction (PCR), and ClonExpress Ultra One Step Cloning Kit applied for plasmid construction were bought from Vazyme (Nanjing, China). Restriction endonucleases and T4 DNA ligase for plasmid construction were purchased from Thermo Scientific (Beijing, China). PCR primers were synthesized by GENEWIZ (Suzhou, China) and listed in Additional file 1: Table S1.

\section{Plasmids and strains construction}

The plasmids and strains used in this study were listed in Table 1.

For reconstruction of 3-phenylpropanol downstream pathway, codon-optimized genes encoding candidates CARs, PPTases and PALs were fully synthesized by Genscript (Nanjing, China). The nucleotide sequences of codon optimized genes were listed in Additional file 1: Table S2. The gene encoding CaER was cloned into pCDFDuet-1 at sites of restriction endonucleases $\mathrm{NcoI}$ and $\mathrm{BamHI}$, resulting an intermediate plasmid pCDF-CaER. The gene encoding EcPPTase was cloned into pCDFDuet-1 using restriction endonucleases NdeI and $B g l \mathrm{II}$ to generate plasmid pQFA01. Genes encoding SruCAR, MsCAR, SroCAR, TtCAR and NcCAR were cloned into pETDuet-1 using NcoI and BamHI to generate plasmids pQFA02, pQFA03, pQFA04, pQFA05, and pQFA06, respectively. Similarly, plasmids pQFA07 and pQFA08 were obtained by cloning genes encoding candidate BsPPTases and NiPPTase into pCDF-CaER at the sites NdeI and BglII, respectively. And plasmids pQFA09, pQFA10 and pQFA11 were obtained by cloning genes encoding TpPAL1, AtPAL2 and ZmPAL2 into plasmid pRSFDuet-1 at the sites $\mathrm{NcoI}$ and BamHI, respectively. Plasmid PQFA12 were obtained by cloning genes encoding RgTAL into plasmid pRSFDuet-1 at the sites EcoRI and HindIII. Plasmid PQFA13 were obtained by cloning genes encoding SriPAL into plasmid pRSFDuet-1 at the sites NdeI and BglII. E. coli BL21 (DE3) was transformed with pQFA01 in combination with pQFA02, pQFA03, pQFA04, pQFA05, and pQFA06 to generated strains 
Table 1 Bacterial strains and plasmids used in this study

\begin{tabular}{|c|c|c|}
\hline Name & Characteristics & Sources \\
\hline \multicolumn{3}{|l|}{ Strains } \\
\hline E. coli BL21(DE3) & 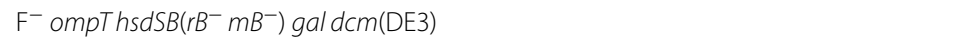 & Invitrogen \\
\hline E. coli BW25113 & $\operatorname{lac}^{1}{ }^{9} r r n B_{\mathrm{T} 14} \Delta l a c Z_{\mathrm{WJ16}} h s d R 514 \Delta \operatorname{araBAD}_{\mathrm{AH} 33} \Delta r h a B A D_{\mathrm{LD} 78}$ & NBRP-E. coli at NIG \\
\hline BWH18 & BW25113, $\Delta$ feaB:: trc $_{\text {trc }}$-aroG $G^{f b r}-p h e A^{f b r}, \Delta t y r A$ & [51] \\
\hline BTR01 & BL21(DE3) with pQFA01 and pQFA02 & This study \\
\hline BTR02 & BL21(DE3) with pQFA01 and pQFA03 & This study \\
\hline BTR03 & BL21(DE3) with pQFA01 and pQFA04 & This study \\
\hline BTR04 & BL21(DE3) with pQFA01 and pQFA05 & This study \\
\hline BTR05 & BL21(DE3) with pQFA01 and pQFA06 & This study \\
\hline BTR06 & BL21(DE3) with pQFA07 and pQFA02 & This study \\
\hline BTR07 & BL21(DE3) with pQFA08 and pQFA02 & This study \\
\hline BTR08 & BTR01 with pQFA09 & This study \\
\hline BTR09 & BTR01 with pQFA10 & This study \\
\hline BTR10 & BTR01 with pQFA11 & This study \\
\hline BTR11 & BTR01 with pQFA12 & This study \\
\hline BTR12 & BTR01 with pQFA13 & This study \\
\hline BTR13 & BWH18 with T7 RNA polymerase gene in the chromosome & This study \\
\hline BTR14 & BTR13, AptsG & This study \\
\hline BTR15 & BTR14, $\triangle p y k A$ & This study \\
\hline BTR16 & BTR15, $\Delta p y k F$ & This study \\
\hline BTR17 & BTR14, $\Delta$ tyrR & This study \\
\hline BTR18 & BTR15, $\Delta$ tyrR & This study \\
\hline BTR19 & BTR16, $\Delta t y r R$ & This study \\
\hline BTR20 & BTR13 with pQFA01, pQFA02 and pQFA10 & This study \\
\hline BTR21 & BTR14 with pQFA01, pQFA02 and pQFA10 & This study \\
\hline BTR22 & BTR15 with pQFA01, pQFA02 and pQFA10 & This study \\
\hline BTR23 & BTR16 with pQFA01, pQFA02 and pQFA10 & This study \\
\hline BTR24 & BTR17 with pQFA01, pQFA02 and pQFA10 & This study \\
\hline BTR25 & BTR18 with pQFA01, pQFA02 and pQFA10 & This study \\
\hline BTR26 & BTR19 with pQFA01, pQFA02 and pQFA10 & This study \\
\hline BTR27 & BTR16 with $\mathrm{P}_{\mathrm{T}}-$-ECPPTase fragment integrated into the locus between entD and ins $L 1$ & This study \\
\hline BEL09 & BTR27, pCDF-CaER, pQFA02, pQFA10 & This study \\
\hline BTR28 & BTR27 with PQFA10 and pQFA14 & This study \\
\hline BTR29 & BTR27 with pQFA15 and pQFA02 & This study \\
\hline BTR30 & BTR27 with pQFA15 and pQFA16 & This study \\
\hline BTR31 & BTR27 with pQFA17 and pQFA18 & This study \\
\hline BTR32 & BTR27 with pQFA19 and pQFA20 & This study \\
\hline BTR33 & BTR27 with pQFA21 and pQFA22 & This study \\
\hline BTR34 & BTR27 with pQFA21 and pQFA16 & This study \\
\hline \multicolumn{3}{|l|}{ Plasmids } \\
\hline pCDFDuet-1 & CDF ori with $\mathrm{P}_{\mathrm{T} 7} ; \mathrm{Str}^{\mathrm{R}}$ & Novagen \\
\hline pETDuet-1 & ColE1 ori with $\mathrm{P}_{\mathrm{T} 7} ; \mathrm{Amp}^{\mathrm{R}}$ & Novagen \\
\hline pRSFDuet-1 & RSF ori with $\mathrm{P}_{\mathrm{T}} ; \mathrm{Kan}^{\mathrm{R}}$ & Novagen \\
\hline pREDCas9 & $\begin{array}{l}\text { pSC101 } 1^{\text {ts }} \text {, pLac- } \lambda \text {-Red, Cas9, ParaBAD } \\
\text {-gRNA-bla Spc }\end{array}$ & [62] \\
\hline pGRB & pUC18 for gRNA construction & [62] \\
\hline PQFA01 & pCDFDuet-1 harboring genes encoding CaER and EcPPTase & This study \\
\hline pQFA02 & pETDuet-1 harboring the gene encoding SruCAR & This study \\
\hline pQFA03 & pETDuet-1 harboring the gene encoding MsCAR & This study \\
\hline pQFA04 & pETDuet-1 harboring the gene encoding SroCAR & This study \\
\hline
\end{tabular}


Table 1 (continued)

\begin{tabular}{lll}
\hline Name & Characteristics & Sources \\
\hline pQFA05 & pETDuet-1 harboring the gene encoding TtCAR & This study \\
pQFA06 & pETDuet-1 harboring the gene encoding NcCAR & This study \\
pQFA07 & pCDFDuet-1 harboring genes encoding CaER and BsPPTase & This study \\
pQFA08 & pCDFDuet-1 harboring genes encoding CaER and NiPPTase & This study \\
pQFA09 & pRSFDuet-1 harboring the gene encoding TpPAL1 & This study \\
pQFA10 & pRSFDuet-1 harboring the gene encoding AtPAL2 & This study \\
pQFA11 & pRSFDuet-1 harboring the gene encoding ZmPAL2 & This study \\
pQFA12 & pRSFDuet-1 harboring the gene encoding RgTAL & This study \\
pQFA13 & pRSFDuet-1 harboring the gene encoding SriPAL & This study \\
PQFA14 & pETDuet-1 harboring genes encoding SruCAR and CaER & This study \\
PQFA15 & pRSFDuet-1 harboring genes encoding AtPAL2 and CaER & This study \\
PQFA16 & pCDFDuet-1 harboring the gene encoding SruCAR & This study \\
PQFA17 & pETDuet-1 harboring the gene encoding AtPAL2 & This study \\
pQFA18 & pRSFDuet-1 harboring genes encoding SruCAR and CaER & This study \\
pQFA19 & pETDuet-1 harboring genes encoding SruCAR and AtPAL2 & This study \\
pQFA20 & pRSFDuet-1 harboring the gene encoding CaER & This study \\
pQFA22 & pETDuet-1 harboring genes encoding AtPAL2 and CaER & This study \\
\hline
\end{tabular}

BTR01, BTR02, BTR03, BTR04, and BTR05, respectively. Strains BTR06-BTR12 were constructed by co-transforming various combinations of expression plasmids as indicated in Table 1.

For combinatorial chromosome engineering of L-phenylalanine producing strains, genes integration and deletion on E. coli BWH18 chromosome [51] were realized by CRISPR-Cas9 meditated genome editing method [62]. In Additional file 1: Table S1, we listed the guide RNA sequences and the primers for construction of corresponding plasmid pGRB and donor DNA. We integrated T7 RNA polymerase gene into the locus between $y b h C$ and $y b h B$ on BWH18 chromosome to obtain strain BTR13. We sequentially deleted genes $p t s G, p y k A, p y k F$ in BTR13 chromosome to generate strains BTR14, BTR15 and BTR16, respectively. The gene tyrR was disrupted in the chromosome of strains BTR14, BTR15 and BTR16 to generate strains BTR17, BTR18 and BTR19, respectively. For de novo production of 3-phenylpropanol, three plasmids pQFA01, pQFA02 and pQFA10, were cotransformed into strains BTR13-BTR19 to construct BTR20-BTR26, respectively.

For metabolic strength balancing of downstream 3-phenylpropanol pathway, the gene encoding EcPPTase under $\mathrm{T}_{7}$ promoter was cloned from pQFA01 and integrated into the locus between entD and insL1 on BTR16 chromosome to obtain strain BTR27, according to CRISPR-Cas9 meditated genome editing method [62]. The pathway genes encoding AtPAL2, CaER and SruCAR were modulated in plasmids pRSFDuet-1, pETDuet-1 or pCDFDuet-1. We used a two-fragment assembling method for construction of plasmids pQFA14-pQFA22 according to the guideline of ClonExpress Ultra One Step Cloning Kit (Vazyme, Nanjing, China), and the primers were listed in Additional file 1: Table S1. All expression vectors harboring two genes were constructed in bicistronic pattern. Strains BTR28-BTR34 were constructed by cotransformation of two expression vectors harboring all three pathway genes (Fig. 5).

\section{Cultivation media and conditions}

For strain cultivation and seed preparation, Luria broth (LB) medium containing $10 \mathrm{~g} / \mathrm{L}$ tryptone, $5 \mathrm{~g} / \mathrm{L}$ yeast extract, and $10 \mathrm{~g} / \mathrm{L} \mathrm{NaCl}$ was used. For fermentations, M9 medium containing $17.1 \mathrm{~g} / \mathrm{L} \quad \mathrm{Na}_{2} \mathrm{HPO}_{4} \cdot 12 \mathrm{H}_{2} \mathrm{O}$, $3.0 \mathrm{~g} / \mathrm{L} \mathrm{KH_{2 }} \mathrm{PO}_{4}, 0.5 \mathrm{~g} / \mathrm{L} \mathrm{NaCl}, 1.0 \mathrm{~g} / \mathrm{L} \mathrm{NH}_{4} \mathrm{Cl}, 5 \mathrm{mM}$ $\mathrm{MgSO}_{4}, 0.1 \mathrm{mM} \mathrm{CaCl}$ and $2 \mathrm{mg} / \mathrm{L}$ vitamin $\mathrm{B} 1$ (pH 7.2) was used. $1 \mathrm{~g} / \mathrm{L}$ and $5 \mathrm{~g} / \mathrm{L}$ yeast extract were added in M9 medium when E. coli BL21(DE3) and E. coli BW25113 derived strains were employed as the host, respectively. $200 \mathrm{mg} / \mathrm{L}$ cinnamic acid was added for screening CARs and PPTases. $500 \mathrm{mg} / \mathrm{L} \mathrm{L}$-phenylalanine was added for screening PALs. Antibiotics were added to the medium as following concentrations when needed: $100 \mu \mathrm{g} / \mathrm{mL}$ ampicillin, $30 \mu \mathrm{g} / \mathrm{mL}$ streptomycin and $30 \mu \mathrm{g} / \mathrm{mL}$ kanamycin.

For fermentation experiments, bacterial clones were transferred into $5 \mathrm{~mL} \mathrm{LB}$ medium and cultivated at $37^{\circ} \mathrm{C}$ and $220 \mathrm{rpm}$. The overnight culture was diluted at 1:100 into $25 \mathrm{~mL} \mathrm{LB}$ medium of $250 \mathrm{~mL}$ shake-flask and cultivated for $6-8 \mathrm{~h}\left(37^{\circ} \mathrm{C}, 220 \mathrm{rpm}\right)$. Then cells were 
collected by centrifugation and resuspended into $25 \mathrm{~mL}$ of M9Y medium at an initial $\mathrm{OD}_{600}$ of 1 . The fermentation was performed under $30{ }^{\circ} \mathrm{C}$ and $220 \mathrm{rpm}$ with $10 \mathrm{~g} / \mathrm{L}$ glucose and $0.1 \mathrm{mM}$ IPTG supplemented if not indicated. For optimization of culture conditions, the fermentation was carried out under different temperatures and supplemented with glucose-glycerol mixture at designed ratios. The experiments were carried out in triplicates and the data was shown as means \pm S.D.

\section{Biomass and metabolite analysis}

Cell optical density (OD) was observed at $600 \mathrm{~nm}$ using a TU-1810 spectrophotometer. The fermentation broth was sampled by directly centrifuged, then the supernatant was filtered and analyzed by a Hitachi Primaide HPLC system (Japan). 3-Phenylpropanol, cinnamic acid, 3-phenylpropionic acid, 3-phenylpropyl aldehyde, cinnamyl alcohol and L-phenylalanine were separated by a Thermo Scientific Hypersil BDS C18 column $(150 \times 4.6 \mathrm{~mm}, 5 \mu \mathrm{m})$ and measured by a PDA detector at $210 \mathrm{~nm}$ with a mobile phase (20\% acetonitrile, $80 \%$ water, $0.1 \%$ trifluoroacetic acid) at $1 \mathrm{~mL} / \mathrm{min}$. Glucose and glycerol were measured by a Morphling ${ }^{\mathrm{TM}}$ Sugar-H column $(300 \times 7.8 \mathrm{~mm}, 5 \mu \mathrm{m})$ and a RI detector with a mobile phase $\left(5 \mathrm{mM} \mathrm{H}_{2} \mathrm{SO}_{4}\right)$ at $0.6 \mathrm{~mL} / \mathrm{min}, 65^{\circ} \mathrm{C}$. All of aforementioned compounds were quantified by HPLC analysis using a five-point calibration curve with the $R^{2}$ coefficient higher than 0.99. GC-MS analysis for 3-phenylpropanol identity was conducted by Agilent Technologies gas chromatography-triple quadrupole tendem mass spectrometry 7890B-7000D. The oven temperature was initially held at $50^{\circ} \mathrm{C}$ for $4 \mathrm{~min}$. Next the temperature was increased at $5{ }^{\circ} \mathrm{C} / \mathrm{min}$ to $150{ }^{\circ} \mathrm{C}$ and then at $90{ }^{\circ} \mathrm{C} /$ min to $250{ }^{\circ} \mathrm{C}$. Temperatures of the injection port and the ionizing source were $250{ }^{\circ} \mathrm{C}$ and $280^{\circ} \mathrm{C}$, respectively. The split ratio was $10: 1$ and $1 \mu \mathrm{L}$ of sample was injected.

\section{Supplementary Information}

The online version contains supplementary material available at https://doi. org/10.1186/s12934-021-01615-1.

Additional file 1: Table S1. The main primers used in this study. Table S2. Nucleotide sequences of codon optimized genes used in this study. Figure S1. GC-MS analysis for identification of 3-phenylpropanol.

\section{Acknowledgements}

The authors are grateful for the financial support from the Key-Areas Research and Development Program of Guangdong Province (2020B0303070002), China.

\section{Authors' contributions}

ZL and GRZ designed the study. ZL performed the experiments. XZ, DL and $\mathrm{BQ}$ assisted in mass spectrometry analysis. ZL and GRZ analyzed the data and drafted the manuscript. All authors read and approved the final manuscript.

\section{Funding}

This work was supported by the Key-Areas Research and Development Program of Guangdong Province (2020B0303070002), China.

\section{Availability of data and materials}

All data generated or analyzed during this study are included in this article and in the Additional file 1.

\section{Declarations}

Ethics approval and consent to participate

Not applicable.

\section{Consent for publication}

Not applicable.

\section{Competing interests}

The authors declare that they have no competing interests.

\section{Author details}

${ }^{1}$ Frontier Science Center for Synthetic Biology and Key Laboratory of Systems Bioengineering (Ministry of Education), School of Chemical Engineering and Technology, Tianjin University, Yaguan Road 135, Jinnan District, Tianjin 300350, China. ${ }^{2}$ Georgia Tech Shenzhen Institute, Tianjin University, Tangxing Road 133, Nanshan District, Shenzhen 518071, China.

Received: 16 March 2021 Accepted: 18 June 2021

Published online: 27 June 2021

\section{References}

1. Bhatia SP, Wellington GA, Cocchiara J, Lalko J, Letizia CS, Api AM. Fragrance material review on 3-phenyl-1-propanol. Food Chem Toxicol. 2011;49(Suppl 2):S246-51.

2. McGinty D, Letizia CS, Api AM. Fragrance material review on 3-phenylpropyl acetate. Food Chem Toxicol. 2012;50(Suppl 2):S457-61.

3. Adams SS, Cobb R. Non-steroidal anti-inflammatory drugs. Prog Med Chem. 1967:5:59-138.

4. Demir B, Demir Y, Aksoy I, Kilic OH, Gucyetmez V, Savas HA. Phenprobamate dependence: a case report. Addict Behav. 2015;45:232-3.

5. Zheng YW, Ye P, Chen B, Meng QY, Feng K, Wang W, Wu LZ, Tung CH. Benzene $\mathrm{C}-\mathrm{H}$ etherification via photocatalytic hydrogen-evolution crosscoupling reaction. Org Lett. 2017:19(9):2206-9.

6. Ramsden JI, Heath RS, Derrington SR, Montgomery SL, Mangas-Sanchez J, Mulholland KR, Turner NJ. Biocatalytic N-alkylation of amines using either primary alcohols or carboxylic acids via reductive aminase cascades. J Am Chem Soc. 2019;141(3):1201-6.

7. IFRA (International Fragrance Association). Volume of use survey, February 2008; 2008.

8. Panten J, Surburg H. Flavors and fragrances, 3. aromatic and heterocyclic compounds. In: Ullmann's encyclopedia of industrial chemistry. KGaA, Weinheim: Wiley; 2016. pp. 1-45. https://doi.org/10.1002/14356007.t11_ t02.

9. Nahrwold M. Improved process to obtain 3-phenylpropan-1-ol from natural sources. WO:2020104682, 28 May 2020.

10. Tai YS, Xiong M, Zhang K. Engineered biosynthesis of medium-chain esters in Escherichia coli. Metab Eng. 2015;27:20-8.

11. Chen Z, Huang J, Wu Y, Wu W, Zhang Y, Liu D. Metabolic engineering of Corynebacterium glutamicum for the production of 3-hydroxypropionic acid from glucose and xylose. Metab Eng. 2017;39:151-8.

12. d'Espaux L, Ghosh A, Runguphan W, Wehrs M, Xu F, Konzock O, Dev I, Nhan M, Gin J, Reider Apel A, Petzold CJ, Singh S, Simmons BA, Mukhopadhyay A, García Martín H, Keasling JD. Engineering high-level production of fatty alcohols by Saccharomyces cerevisiae from lignocellulosic feedstocks. Metab Eng. 2017;42:115-25.

13. Liu X, Li XB, Jiang J, Liu ZN, Qiao B, Li FF, Cheng JS, Sun X, Yuan YJ, Qiao J, Zhao GR. Convergent engineering of syntrophic Escherichia coli coculture for efficient production of glycosides. Metab Eng. 2018;47:243-53. 
14. Chatzivasileiou AO, Ward V, Edgar SM, Stephanopoulos G. Two-step pathway for isoprenoid synthesis. Proc Natl Acad Sci USA. 2019;1 16(2):506-11.

15. Cheng S, Liu X, Jiang G, Wu J, Zhang JL, Lei D, Yuan YJ, Qiao J, Zhao GR. Orthogonal engineering of biosynthetic pathway for efficient production of limonene in Saccharomyces cerevisiae. ACS Synth Biol. 2019;8(5):968-75.

16. Flores AD, Ayla EZ, Nielsen DR, Wang X. Engineering a synthetic, catabolically orthogonal coculture system for enhanced conversion of lignocellulose-derived sugars to ethanol. ACS Synth Biol. 2019;8(5):1089-99.

17. Luo X, Reiter MA, d'Espaux L, Wong J, Denby CM, Lechner A, Zhang Y, Grzybowski AT, Harth S, Lin W, Lee H, Yu C, Shin J, Deng K, Benites VT, Wang G, Baidoo EEK, Chen Y, Dev I, Petzold CJ, Keasling JD. Complete biosynthesis of cannabinoids and their unnatural analogues in yeast. Nature. 2019;567(7746):123-6.

18. Luo ZW, Cho JS, Lee SY. Microbial production of methyl anthranilate, a grape flavor compound. Proc Natl Acad Sci USA. 2019;116(22):10749-56.

19. Shukal S, Chen X, Zhang C. Systematic engineering for high-yield production of viridiflorol and amorphadiene in auxotrophic Escherichia coli. Metab Eng. 2019;55:170-8.

20. Gu Y, Ma J, Zhu Y, Xu P. Refactoring Ehrlich pathway for high-yield 2-phenylethanol production in Yarrowia lipolytica. ACS Synth Biol. 2020;9(3):623-3.

21. Milke L, Mutz M, Marienhagen J. Synthesis of the character impact compound raspberry ketone and additional flavoring phenylbutanoids of biotechnological interest with Corynebacterium glutamicum. Microb Cell Fact. 2020;19(1):92.

22. Palmer CM, Miller KK, Nguyen A, Alper HS. Engineering 4-coumaroylCoA derived polyketide production in Yarrowia lipolytica through a B-oxidation mediated strategy. Metab Eng. 2020;57:174-81.

23. Gottardi M, Knudsen JD, Prado L, Oreb M, Branduardi P, Boles E. De novo biosynthesis of trans-cinnamic acid derivatives in Saccharomyces cerevisiae. Appl Microbiol Biotechnol. 2017;101(12):4883-93.

24. Gottardi M, Grün P, Bode HB, Hoffmann T, Schwab W, Oreb M, Boles E. Optimisation of trans-cinnamic acid and hydrocinnamyl alcohol production with recombinant Saccharomyces cerevisiae and identification of cinnamyl methyl ketone as a by-product. FEMS Yeast Res. 2017. https:// doi.org/10.1093/femsyr/fox091.

25. Klumbys E, Zebec Z, Weise NJ, Turner NJ, Scrutton NS. Bio-derived production of cinnamyl alcohol via a three step biocatalytic cascade and metabolic engineering. Green Chem. 2019;20(3):658-63.

26. Turner NJ, O'Reilly E. Biocatalytic retrosynthesis. Nat Chem Biol. 2013:9(5):285-8.

27. Hadadi N, Hatzimanikatis V. Design of computational retrobiosynthesis tools for the design of de novo synthetic pathways. Curr Opin Chem Biol. 2015;28:99-104.

28. Birmingham WR, Starbird CA, Panosian TD, Nannemann DP, Iverson TM, Bachmann BO. Bioretrosynthetic construction of a didanosine biosynthetic pathway. Nat Chem Biol. 2014;10(5):392-9.

29. Ren J, Zhou L, Wang C, Lin C, Li Z, Zeng AP. An unnatural pathway for efficient 5 -aminolevulinic acid biosynthesis with glycine from glyoxylate based on retrobiosynthetic design. ACS Synth Biol. 2018;7(12):2750-7.

30. Kim DI, Chae TU, Kim HU, Jang WD, Lee SY. Microbial production of multiple short-chain primary amines via retrobiosynthesis. Nat Commun. 2021;12(1):173.

31. Yim H, Haselbeck R, Niu W, Pujol-Baxley C, Burgard A, Boldt J, Khandurina J, Trawick JD, Osterhout RE, Stephen R, Estadilla J, Teisan S, Schreyer HB, Andrae S, Yang TH, Lee SY, Burk MJ, Van Dien S. Metabolic engineering of Escherichia coli for direct production of 1,4-butanediol. Nat Chem Biol. 2011;7(7):445-52.

32. Fehér T, Planson AG, Carbonell P, Fernández-Castané A, Grigoras I, Dariy E, Perret A, Faulon JL. Validation of RetroPath, a computer-aided design tool for metabolic pathway engineering. Biotechnol J. 2014;9(11):1446-57.

33. Delépine B, Duigou T, Carbonell P, Faulon JL. RetroPath2.0: a retrosynthesis workflow for metabolic engineers. Metab Eng. 2018;45:158-70.

34. Duigou T, du Lac M, Carbonell P, Faulon JL. RetroRules: a database of reaction rules for engineering biology. Nucleic Acids Res. 2019;47(D1):D1229-35.

35. Kunjapur AM, Tarasova Y, Prather KL. Synthesis and accumulation of aromatic aldehydes in an engineered strain of Escherichia coli. J Am Chem Soc. 2014;136(33):11644-54
36. Rohdich F, Wiese A, Feicht R, Simon $\mathrm{H}$, Bacher A. Enoate reductases of Clostridia. Cloning, sequencing, and expression. J Biol Chem. 2001:276(8):5779-87.

37. Sun J, Lin Y, Shen X, Jain R, Sun X, Yuan Q, Yan Y. Aerobic biosynthesis of hydrocinnamic acids in Escherichia coli with a strictly oxygen-sensitive enoate reductase. Metab Eng. 2016;35:75-82.

38. Butler N, Kunjapur AM. Carboxylic acid reductases in metabolic engineering. J Biotechnol. 2020;307:1-14

39. Finnigan W, Thomas A, Cromar H, Gough B, Snajdrova R, Adams JP, Littlechild JA, Harmer NJ. Characterization of carboxylic acid reductases as enzymes in the toolbox for synthetic chemistry. ChemCatChem. 2017:9(6):1005-17.

40. Duan Y, Yao P, Chen X, Liu X, Zhang R, Feng J, Wu Q, Zhu D. Exploring the synthetic applicability of a new carboxylic acid reductase from Segniliparus rotundus DSM 44985. J Mol Catal B Enzym. 2015;115:1-7.

41. Horvat M, Fiume G, Fritsche S, Winkler M. Discovery of carboxylic acid reductase (CAR) from Thermothelomyces thermophila and its evaluation for vanillin synthesis. J Biotechnol. 2019;304:44-51.

42. Schwendenwein D, Fiume G, Weber H, Rudroff F, Winkler M. Selective enzymatic transformation to aldehydes in vivo by fungal carboxylate reductase from Neurospora crassa. Adv Synth Catal. 2016;358(21):3414-21.

43. Bai Y, Yin H, Bi H, Zhuang Y, Liu T, Ma Y. De novo biosynthesis of gastrodin in Escherichia coli. Metab Eng. 2016;35:138-47.

44. Beld J, Sonnenschein EC, Vickery CR, Noel JP, Burkart MD. The phosphopantetheinyl transferases: catalysis of a post-translational modification crucial for life. Nat Prod Rep. 2014;31(1):61-108.

45. Nakano MM, Corbell N, Besson J, Zuber P. Isolation and characterization of sfp: a gene that functions in the production of the lipopeptide biosurfactant, surfactin, in Bacillus subtilis. Mol Gen Genet. 1992;232(2):313-21.

46. Barajas JF, Blake-Hedges JM, Bailey CB, Curran S, Keasling JD. Engineered polyketides: synergy between protein and host level engineering. Synth Syst Biotechnol. 2017;2(3):147-66.

47. Wang S, Zhang S, Zhou T, Zeng J, Zhan J. Design and application of an in vivo reporter assay for phenylalanine ammonia-lyase. Appl Microbiol Biotechnol. 2013;97(17):7877-85.

48. Cochrane FC, Davin LB, Lewis NG. The Arabidopsis phenylalanine ammonia lyase gene family: kinetic characterization of the four PAL isoforms. Phytochemistry. 2004;65(11):1557-64.

49. Zang Y, Jiang T, Cong Y, Zheng Z, Ouyang J. Molecular characterization of a recombinant Zea mays phenylalanine ammonia-Lyase (ZmPAL2) and its application in trans-cinnamic acid production from L-phenylalanine. Appl Biochem Biotechnol. 2015:176(3):924-37.

50. Baranasic D, Zucko J, Nair M, Pain A, Long PF, Hranueli D, Cullum J, Starcevic A. Genome sequences of the oxytetracycline production strain Streptomyces rimosus R6-500 and two mutants with chromosomal rearrangements. Genome Announc. 2014;2(4): e00517-14.

51. Liu Z, Lei D, Qiao B, Li S, Qiao J, Zhao GR. Integrative biosynthetic gene cluster mining to optimize a metabolic pathway to efficiently produce L-homophenylalanine in Escherichia coli. ACS Synth Biol. 2020;9(11):2943-54.

52. Flores S, Gosset G, Flores N, de Graaf AA, Bolívar F. Analysis of carbon metabolism in Escherichia coli strains with an inactive phosphotransferase system by (13)C labeling and NMR spectroscopy. Metab Eng. 2002:4(2):124-37.

53. Noda S, Kondo A. Recent advances in microbial production of aromatic chemicals and derivatives. Trends Biotechnol. 2017;35(8):785-96.

54. Meza E, Becker J, Bolivar F, Gosset G, Wittmann C. Consequences of phosphoenolpyruvate:sugar phosphotranferase system and pyruvate kinase isozymes inactivation in central carbon metabolism flux distribution in Escherichia coli. Microb Cell Fact. 2012;11:127.

55. Koma D, Kishida T, Yoshida E, et al. Chromosome engineering to generate plasmid-free phenylalanine- and tyrosine-overproducing Escherichia coli strains that can be applied in the generation of aromatic-compoundproducing bacteria. Appl Environ Microbiol. 2020:86(14): e00525-20.

56. Li M, Liu C, Yang J, Nian R, Xian M, Li F, Zhang H. Common problems associated with the microbial productions of aromatic compounds and corresponding metabolic engineering strategies. Biotechnol Adv. 2020:41: 107548.

57. Pittard J, Camakaris H, Yang J. The TyrR regulon. Mol Microbiol. 2005:55(1):16-26. 
58. Yang J, Ogawa Y, Camakaris H, Shimada T, Ishihama A, Pittard AJ. folA, a new member of the TyrR regulon in Escherichia coli K-12. J Bacteriol. 2007;189(16):6080-4.

59. Bozell JJ, Petersen GR. Technology development for the production of biobased products from biorefinery carbohydrates - the US Department of Energy's "top 10" revisited. Green Chem. 2010;12(4):539-54.

60. Alva A, Sabido-Ramos A, Escalante A, Bolívar F. New insights into transport capability of sugars and its impact on growth from novel mutants of Escherichia coli. Appl Microbiol Biotechnol. 2020;104(4):1463-79.

61. Koch M, Duigou T, Faulon JL. Reinforcement learning for bioretrosynthesis. ACS Synth Biol. 2020;9(1):157-68.
62. Li Y, Lin Z, Huang C, Zhang Y, Wang Z, Tang YJ, Chen T, Zhao X. Metabolic engineering of Escherichia coli using CRISPR-Cas9 meditated genome editing. Metab Eng. 2015;31:13-21.

\section{Publisher's Note}

Springer Nature remains neutral with regard to jurisdictional claims in published maps and institutional affiliations.
Ready to submit your research? Choose BMC and benefit from:

- fast, convenient online submission

- thorough peer review by experienced researchers in your field

- rapid publication on acceptance

- support for research data, including large and complex data types

- gold Open Access which fosters wider collaboration and increased citations

- maximum visibility for your research: over $100 \mathrm{M}$ website views per year

At BMC, research is always in progress.

Learn more biomedcentral.com/submissions 